\title{
Monoclonal Light Chain-Mesangial Cell Interactions: Early Signaling Events and Subsequent Pathologic Effects
}

\author{
William J. Russell, James Cardelli, Edward Harris, R. John Baier, and \\ Guillermo A. Herrera \\ Department of Pathology (WJR, GAH), Department of Microbiology (JC, EH), Department of Pediatrics (RJB), and \\ Departments of Cell Biology and Anatomy and Medicine (GAH), Louisiana State University Health Sciences Center, \\ Shreveport, Louisiana
}

\begin{abstract}
SUMMARY: Glomerulopathic monoclonal light chains (G-LC) interact with mesangial cells (MC), resulting in alterations of mesangial homeostasis. Early signaling events control mitogenic activities and cytokine production, which in turn participate in the subsequent pathologic events. Mesangial homeostasis is affected in two very different ways, depending on whether the G-LC is from a patient with light chain deposition disease (LCDD) or light chain-related amyloidosis (AL-Am). In contrast, tubulopathic (T)-LC chains from patients with myeloma cast nephropathy do not significantly interact with MC and result in no alterations in mesangial homeostasis. Therefore, understanding early events in the monoclonal LC-MC interactions is fundamental. MC in culture were exposed to LC obtained and purified from the urine of patients with plasma cell dyscrasias and biopsy-proven renal disease, including LCDD, AL-Am, and myeloma cast nephropathy. Incubation of MC with G-LC, but not T-LC, resulted in cytoskeletal and cell shape changes, activation of platelet-derived growth factor- $\beta$ (PDGF- $\beta$ ) and its corresponding receptor, cytoplasmic to nuclear migration of $\mathrm{C}-\mathrm{fos}$ and NF- $\kappa \beta$ signals, and production of monocyte chemoattractant protein-1 (MCP-1), as well as increased expression of $\mathrm{Ki}-67$, a proliferation marker. Although NF- $\kappa \beta$ activation was directly related to MCP-1 production, c-fos activation regulated proliferative signals and cytoskeletal changes in MC. Amyloidogenic LC were avidly internalized by the MC, whereas LCDD-LC effector targets were located at the MC surface. These cellular events are likely initiated as a result of interactions of the G-LC with yet-uncharacterized MC surface receptors. Dissecting the events taking place when G-LC interact with MC may define potential important targets for selective therapeutic manipulation to ameliorate or prevent the glomerular injury that ensues. (Lab Invest 2001, 81:689-703).
\end{abstract}

$D$ eposition of free immunoglobulin light chains (LC) within the kidney and the subsequent pathologic alterations that occur cause renal failure in slightly more than half of all patients with plasma cell dyscrasias (Gallo et al, 1989; Sanders et al, 1991; Sanders and Herrera, 1993). Renal failure can result from glomerular injury, proximal tubule damage, or cast nephropathy. In renal biopsies obtained from patients with LC-related renal diseases, LC are detected by electron microscopy within the glomerulus either as distinct granular osmiophilic deposits associated with increased mesangial matrix (light chain deposition disease, LCDD) or as amyloid fibrils (light chain-related amyloidosis, AL-Am) replacing the normal mesangial matrix.

Although in patients with LCDD, a typical nodular glomerulopathy with formation of mesangial nodules resulting from an increase in extracellular matrix ma-

Received November 22, 2000

This work was supported in part by a Leukemia Society of America translational research grant (6198-98).

Address reprint requests to: Dr. Guillermo A. Herrera, Department of Pathology, Louisiana State University Health Sciences Center, 1501 Kings Highway, Shreveport, LA 71130. E-mail: gherre@lsubsc.edu terial (ECM) eventually occurs, the opposite effect takes place in AL-Am, where the normal mesangium is destroyed and replaced by the amyloid fibrils. Tubular (T)-LC do not affect glomeruli. It has been proposed that proteolysis is an integral part of the process of amyloidogenesis. The current research was performed to elucidate the early events that take place as glomerulopathic (G)-LC contact mesangial cells (MC) with emphasis on signaling, internalization, and $\mathrm{MC}$ surface interactions.

$\mathrm{MC}$ are crucial in the pathogenesis of both of these processes. When cultured MC are exposed to monoclonal LC from LCDD patients, transforming growth factor (TGF)- $\beta$ production is increased and extracellular matrix proteins (ECM) such as fibronectin, collagen iv, laminin, and tenascin accumulate. The increase in TGF- $\beta$ inhibits mesangial proliferation and promotes ECM accumulation. Likewise, when LC obtained from patients with AL-Am are incubated with human mesangial cells (HMC), amyloid formation occurs. These in vitro changes mirror the alterations observed in vivo and suggest that the glomerulopathic changes induced in vivo are a function of the type of LC present. In contrast, T-LC do not alter mesangial homeostasis in vitro or in vivo (Herrera et al 1999). 
The entire sequence of events by which LC interact with HMC to induce TGF- $\beta$ production in LCDD and to lead to amyloidogenesis in AL-Am has not been entirely elucidated. Short-term signaling events and long-term effector mechanisms must take place to account for the initial and subsequent long-lasting alterations, respectively, that occur as G-LC interact with MC. Incubation of G-LC with MC causes pronounced cellular membrane ruffling within minutes. Concomitantly, ultrastructural immunogold labeling revealed that the G-LC interacted with the $\mathrm{MC}$ membrane via structures morphologically resembling clathrin-coated pits initiating signaling events that ultimately result in transmission of cytoplasmic signals to the MC nuclei to generate translational activities associated with activation of growth factors (Abboud, 1993; Herrera et al, 1994; Zhu et al, 1995). Although internalization is not an important event in LCDDLC-MC interactions, in AL-Am earlier studies have shown that internalization and endolysosomal processing of the LC is a prerequisite for amyloid formation (Tagouri et al, 1996). This would suggest that a receptor at a binding site exists on the MC surface for the internalization of $\mathrm{LC}$ in $\mathrm{AL}-\mathrm{Am}$ and to initiate cell-signaling events resulting in the ECM expansion observed in LCDD. It is also possible that these processes, the internalization of $L C$ in $A L-A m$ and the ECM expansion in LCDD, are mediated by different LC receptors. The process of binding of different $L C$ to the MC surface was examined by flow cytometry to characterize LC-MC interactions. Signaling mechanisms involved in LC-MC interactions were also explored in an attempt to determine whether there were any differences among G-LC and T-LC, and between LCDD and amyloid-producing LC.

$\mathrm{MC}$ have been determined to be among the cell types that can produce MCP-1 (Duque et al, 1997; Rovin et al, 1995, 1999; Ruiz-Ortega et al, 1998; Stylianou et al, 1999). The intracellular signals that regulate $\mathrm{MCP}-1$ expression in response to exogenous stimuli are not completely characterized. However, previous studies have demonstrated that activation of the transcription factor $\mathrm{NF}-\kappa \beta$ is necessary for interleukin-1 (IL-1)-induced MCP-1 expression (Richards et al, 1999; Rovin et al, 1999). Mitogenic stimuli, such as the platelet-derived growth factor- $\beta$ (PDGF$\beta$-mediated effect on MC on exposure to G-LC documented to occur early in the "in-vitro" system and by the localization of PDGF- $\beta$ in mesangial areas in biopsy specimens (Herrera et al, 1994), activate the ribosomal S6 kinase 1 (RSK1) through the pathway involving the extracellular signal-regulated kinase (ERK) subfamily of mitogen-activated protein (MAP) kinases. RSK plays an important role in nuclear signaling by phosphorylating various transcription factors, including c-fos, and is also implicated in cellcycle regulation (Richards et al, 1999). PDGF has also been shown to induce ruffling in fibroblasts (Mellström et al 1988). This suggests a role for c-fos in signaling events controlling MC proliferation and cytoskeletal actin rearrangement leading to surface ruffling. The role of transcription factors such as NF- $\kappa \beta$ and c-fos in MC interacting with G-LC was also explored.

\section{Results}

\section{Testing of Purified LC for Endotoxins}

No gelation was observed when all purified LC used in the present study at a concentration of $1 \mathrm{mg} / \mathrm{ml}$ were assayed, indicating the absence of endotoxins at the sensitivity limit dictated by the methodology. Positive and negative controls tested as expected with detectable endotoxin levels at 0.125 to $100 \mathrm{EU} / \mathrm{ml}$ in the positive control specimens and no gelation with negative controls.

\section{Binding of LC to HMC}

The binding of a LCDD-LC (And), and AL-LC (Hac), and a T-LC (Jon) to HMC in normal RPMI 1640 was examined at room temperature and at $37^{\circ} \mathrm{C}, \mathrm{pH} 7.4$. After a 30 - or 90-minute incubation period, a small increase in the percentage of FITC gated fluorescent cells was detected only after the addition of the LCDD-LC to HMC (Fig. 1). No increase in the percentage of gated R-PE fluorescent cells was detected when the AL-LC, or the T-LC were added to HMC (Fig. 1). The binding of LCDD-LC to HMC was actually slightly more at $37^{\circ} \mathrm{C}$ than at room temperature.

LC binding was subsequently examined at $25^{\circ} \mathrm{C}$ and $37^{\circ} \mathrm{C}$ after the RPMI had been acidified to $\mathrm{pH} 5.0$ to inhibit clathrin-mediated endocytosis of LC. Under these conditions, the increase in the percentage of gated cells binding either of the two G-LC, And or Hac, was substantially higher than that for the T-LC, Jon (Fig. 2). When LC were incubated with $\mathrm{HMC}$ at $4^{\circ} \mathrm{C}$ or in medium made hypertonic with $250 \mathrm{~mm}$ sucrose, a slight increase in percentage of gated cells to which

\section{Light Chain Binding to Mesangial Cells (pH 7.4)}
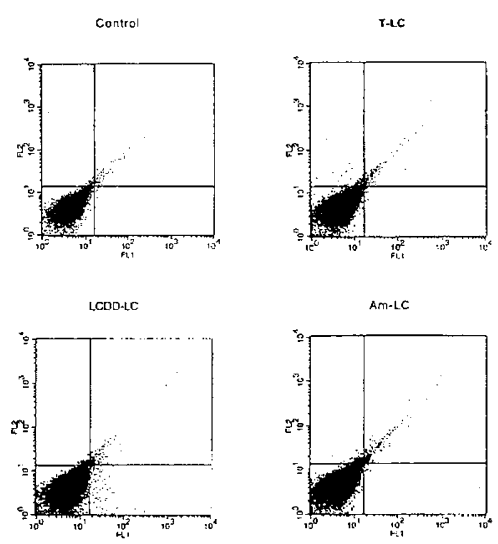

Figure 1.

Light chain (LC) binding to mesangial cells (MC) at pH 7.4. Flow cytometry. Control, tubulopathic (T)-LC and amyloidogenic (AL)-LC show no significant binding to MC at pH 7.4. In contrast, light chain deposition disease (LCDD)-LC binds to $\mathrm{MC}$ at $\mathrm{pH} 7.4$ as demonstrated in the right lower gate (quadrant), of the LCDD-LC flow cytometry chart. 


\section{Light Chain Binding to Mesangial Cells (pH 5.0)}
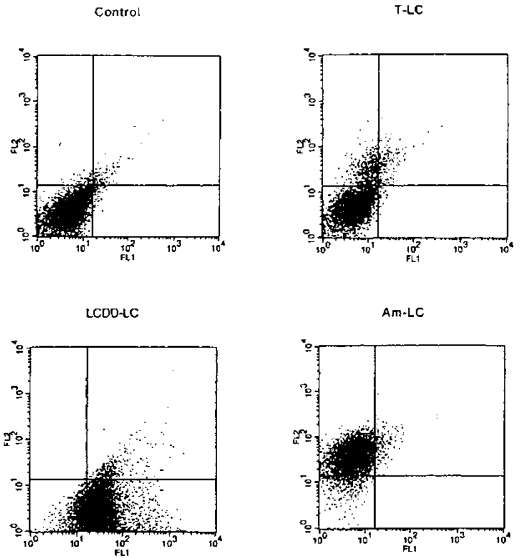

\section{Figure 2.}

Light chain binding to $\mathrm{MC}$ at $\mathrm{pH} 5$ (inhibition of clathrin-mediated endocytosis). Flow cytometry. Am (AL)-LC are detected at the MC surface when clathrin-mediated endocytosis is inhibited at $\mathrm{pH}$ 5. There is also a significant increase in detectable LC at the MC surface in LCDD-LC, but not as dramatic as with the $A m(A L)-L C$, and no significant increase is noted for the T-LC.

the G-LC, And or Hac, were bound was detected as compared with the T-LC, Jon. These conditions, which should have also disrupted clathrin-mediated uptake of LC, were not as effective in increasing the amount of LC bound to $\mathrm{HMC}$ as acidification of the cytosol.

The binding of LC to fetal HMC, mouse fibroblasts (L) cells, and Chinese hamster ovary $(\mathrm{CHO})$ cells was compared at $\mathrm{pH} 7.4$ and $\mathrm{pH} 5.0$ to examine the specificity of the binding of the AL-LC, Hac, to these different cell lines. As observed for adult HMC, acidification of the medium resulted in a dramatic increase in the percentage of gated R-PE fluorescent that could be detected after addition of Hac to fetal HMC (Fig. 3). In contrast, acidification of the medium produced a marginal increase in the percentage of R-PE fluorescent cells for $L$ cells, and minimal if any change in binding to $\mathrm{CHO}$ cells (Fig. 3 ).

\section{Direct Fluorescence Microscopy}

MC incubated with G-LC exhibited striking surface ruffling associated with prominent cytoskeletal actin reorganization, as detected when stained with Texas red-phalloidin. Approximately $20 \%$ and $10 \%$ of all the $M C$ exposed to G-LC (LCDD and AL-LC), respectively, exhibited ruffling and cytoskeletal actin reorganization (Figs. 4, A to C, and 5) with maximum effect noted at 40 to 45 minutes. The number of $M C$ with ruffling increased as time of incubation with G-LC was prolonged up to approximately 45 minutes. MC incubated with albumin did not show surface ruffling or significant actin reorganization. HMC incubated with T-LC showed ruffling in less than $1 \%$ of the cells.

\section{Ultrastructural Studies}

Surface ruffling was identified in an average of $18 \%$ of MC incubated with either LCDD or AL-LC. In contrast, less than $1 \%$ of MC incubated with albumin or T-LC showed evidence of surface ruffling. Ruffling was at first noted circumferentially in the MC within 20 to 30 minutes after the initial application of G-LC (LCDD and $\mathrm{AL}-\mathrm{LC}$ ), and in approximately 60 to 90 minutes the

\section{Am-Light Chain Interactions with Other Cell Types}
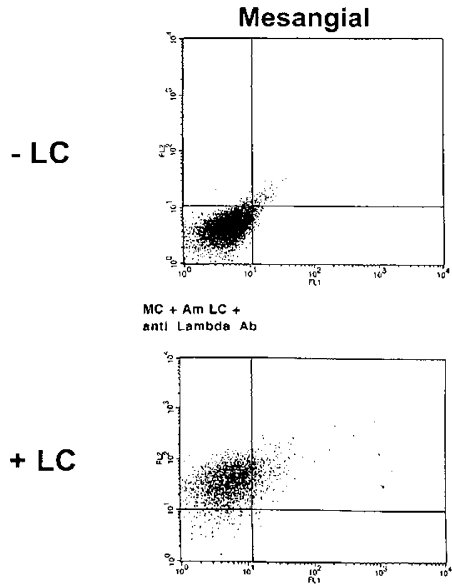

$M C+$ Am $L C+$
antl Lambda $A$

\section{Cell Lines}

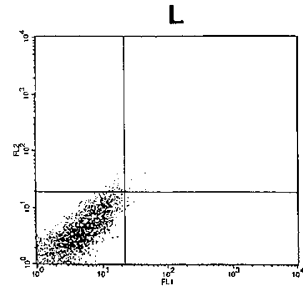

L(1K-)
Lambda
ant
Ab

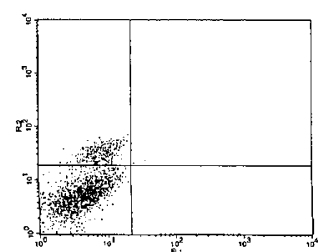

$L($ (TK-) $+A M L C+$
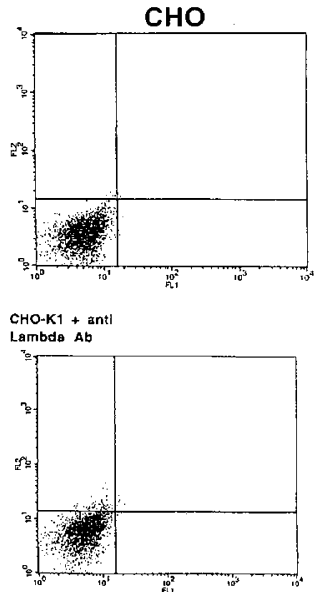

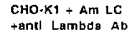

Figure 3.

$\mathrm{Am}(\mathrm{AL})$-light chain interactions with other cell types at pH 5. Flow cytometry. Note that the interaction of $\mathrm{Am}(\mathrm{AL})$ - $L C$ is rather specific with $\mathrm{MC}$ and does not occur with $\mathrm{L}$ or $\mathrm{CHO}$ cells. Interaction with fetal MC (left panel) are also shown and mimics the results observed with adult human mesangial cells (HMC). L, mouse fibroblasts; $\mathrm{CHO}$, Chinese hamster ovary. 

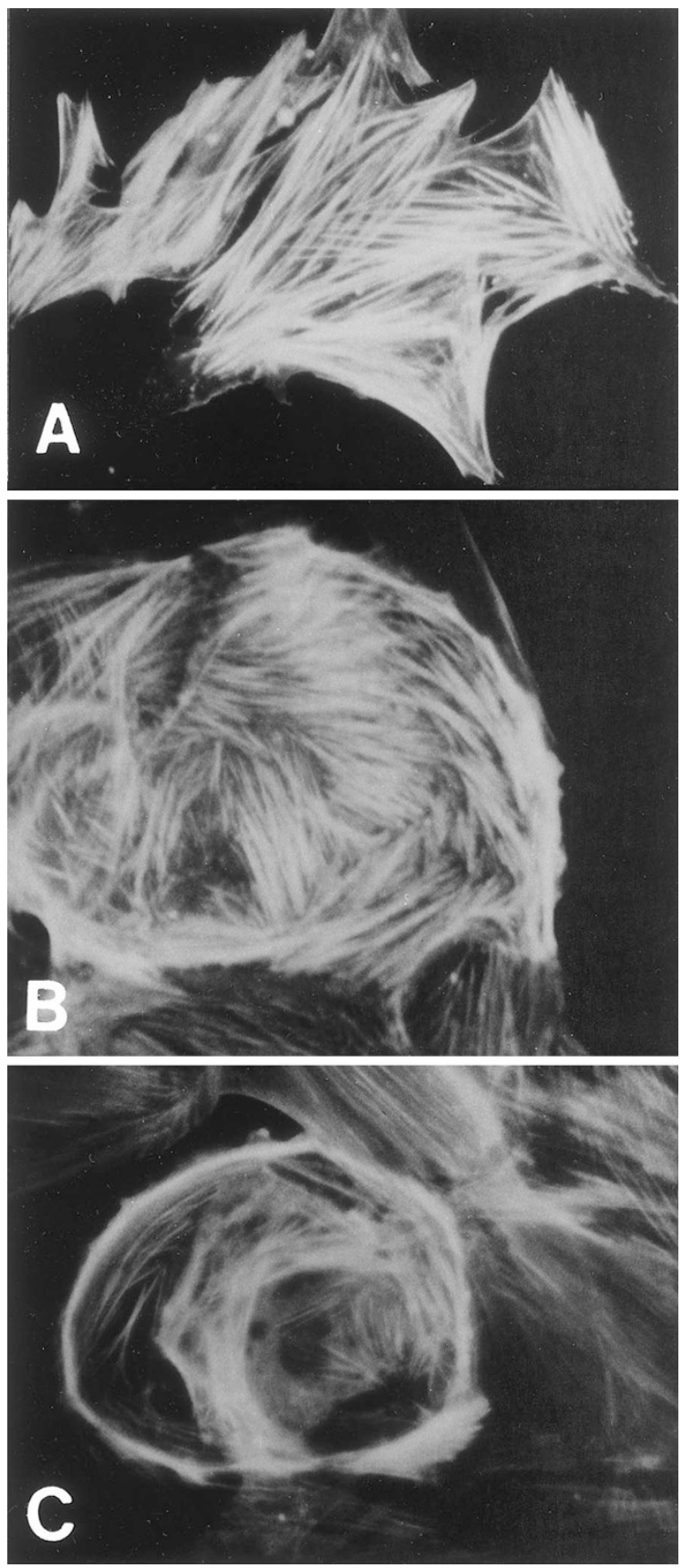

Figure 4.

Texas red-phalloidin fluorescence stain. Early cytoskeletal changes in MC incubated with G-LC. A, B, and C, Sequential alterations in the F-actin distribution in the cytoskeletal framework of MC. Original magnification, $A$, $\times 500$; B, $\times 500 ;$ C, $\times 500$.

surface ruffling became localized to focal cellular areas (Fig. 6, A and B). Dense areas with accumulation of filaments consistent with actin were noted underneath the areas of ruffling once the surface alterations became localized to focal areas in the MC (Fig. 6B).

\section{NF-кB 65p and c-fos Immunolocalization in HMC}

In $\mathrm{HMC}$ in culture, NF- $\kappa \mathrm{B}$ and $\mathrm{c}$-fos were detected diffusely in the cytoplasm (Fig. 7, A and E). No nuclear fluorescence staining was noted. On exposure to
G-LC $(10 \mu \mathrm{g} / \mathrm{ml})$, but not T-LC, the NF- $\kappa \beta$ and c-fos signals disappeared from the cytoplasm, migrating to the nuclei within 20 minutes of exposure to the LC, indicating redistribution of the signaling molecules. The nuclear signal was detected in $20 \%$ to $30 \%$ of MC incubated with LCDD-LC (Fig. 7, B and F). In contrast, less than $10 \%$ of $\mathrm{MC}$ reflected the cytoplasmic to nuclear migration of the NF- $\kappa \beta$ signal and c-fos signals when incubated with AL-LC (Fig. 7, C and G). Interestingly, migration of $\mathrm{c}$-fos (but not NF- $\kappa \beta$ ) from cytoplasm to nucleus occurred in the same cells with cytoskeletal actin reorganization and ruffling. Furthermore, when MC were exposed to T-LC at the same LC concentration, the NF- $\kappa \beta$ and $\mathrm{c}$-fos signals remained in a cytoplasmic location (Fig. 7, D and H). Only in very rare $\mathrm{MC}$ (much less than $1 \%$ of all $\mathrm{MC}$ ), the NF- $\kappa \beta$ and $c$-fos signals were detected in nuclei $(p<0.05)$.

\section{Western Analysis of Nuclear Protein Extracts for NF-к及 $65 p$ in HMC}

Distinct bands corresponding to NF- $\kappa \beta$ 65p were demonstrated by Western analysis in the nuclear extracts of HMC treated with LCDD (And), AL (Bel, Hac), and T-LC (Jon) at 6 and 12 hours after application of LC. The intensity of the band with the LCDD-LC was more pronounced than that noted with the AL-LC and T-LC. The NF- $\kappa \beta$ 65p bands obtained in the nuclear extracts of AL-LC-treated HMC were more distinct than those noted with the T-LC or media alone at the same time frame. Those findings are consistent with the results noted using immunofluorescence techniques monitoring translocation of NF- $\kappa \beta$ signals from cytoplasm to nuclei of HMC on exposure to LC. The intensity of the bands noted in HMC incubated with media alone at 0,6 , and 12 hours were similar to the band seen with the T-LC (Fig. 8).

\section{MCP-1 Measurements in HMC Cultures}

HMC exposed to LCDD-LC (And) showed the highest MCP-1 concentrations at 3, 6, and 12 hours after LC application when compared with media, AL-LC (Bel), T-LC (Jon), and BSA. Samples treated with AL-LC also showed increased MCP-1 concentrations as compared with media and T-LC $(p<0.05)$, but always less than LCDD-LC-treated samples $(p<0.05)$. MCP-1 concentrations in specimens treated with T-LC were similar to those in HMC in media alone with no LC at 3,6 , and 12 hours after application (Table 1).

\section{Tumor Necrosis Factor- $\alpha$ Measurements in HMC}

Tumor necrosis factor (TNF)- $\alpha$ was below 8 (the level of detection of the ELISA test) in all experimental and control specimens, including those in which $\mathrm{HMC}$ were incubated with LCDD, AL-LC, and T-LC for 3, 6, 12,24 , and 48 hours, as well as in control samples incubated with media alone with no LC for the same times. 


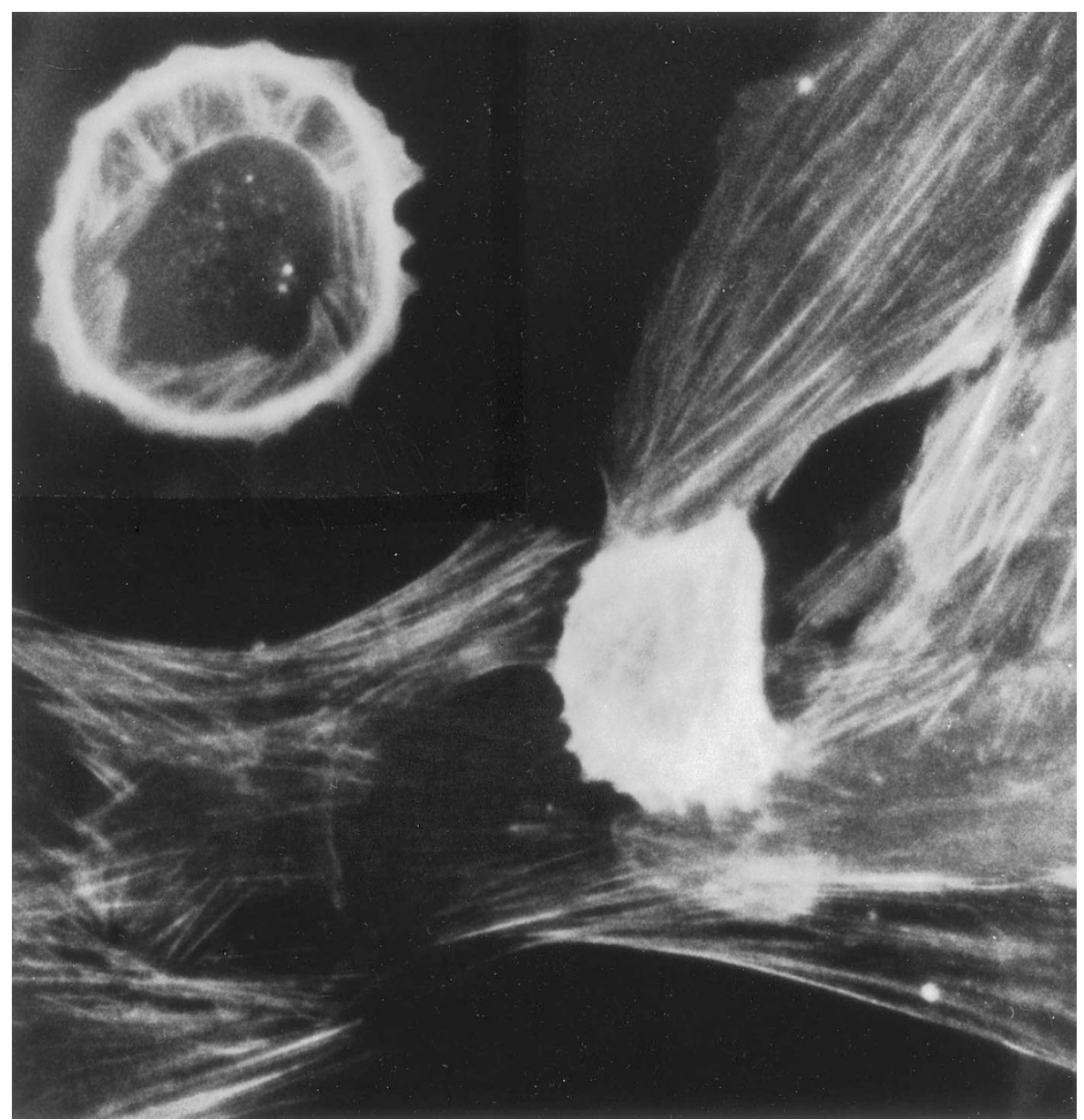

Figure 5.

Texas red-phalloidin fluorescence stain. Note that only some MC alter their cytoskeletal appearance when exposed to G-LC. Also noted circumferential ruffling that occurs after the initial changes depicted in Figure 4. Original magnification, $\times 350$; insert, $\times 500$.

\section{Immunohistochemistry Staining for Ki-67 Nuclear Antigens Associated with Proliferation}

The percentage of Ki-67-positive nuclei in HMC was calculated in each of the experimental conditions and compared with untreated HMC (with media alone). Results are shown in Table 2. At all time frames, HMC incubated with LCDD-LC had the highest percentage of Ki-67 staining cells, followed by those treated with AL-LC. HMC treated with T-LC had a proliferation rate similar to those incubated with no LC (media alone). As expected, HMC incubated with PDGF-BB (a growth factor known to stimulate MC proliferation) had the highest of all the Ki-67 counts. The percentage of Ki-67-positive HMC increased from 1 to 24 hours, with the highest percentages detected at 24 hours in all experimental conditions (Table 2). Incubation with anti-c-fos before LCDD-LC stimulation decreased Ki-67 staining of HMC by approximately half $(p<$ $0.05)$. MC surface ruffling was decreased similarly. A similar but slightly less pronounced decrease in Ki-67 staining and $\mathrm{MC}$ cytoskeletal changes was noted when $M C$ were preincubated with anti-c-fos before PDGF-BB stimulation $(p<0.05)$. The differences in $\mathrm{Ki}-67$ staining and surface ruffling in $\mathrm{HMC}$ preincu- bated with anti-C-fos before AL-LC and T-LC stimulation were not statistically significant. (Table 3, Fig. 9).

\section{Immunohistochemical Staining for PDGF- $\beta$, PDGF- $\beta$ Receptor, and TGF- $\beta$}

The most intense staining for PDFG and PDFG- $\beta$ receptor was noted at 1 day, whereas the most intense staining for TGF- $\beta$ was observed at 3 days after LC application, at a time when the staining for PDGF- $\beta$ and the corresponding receptor was much decreased when compared with the peak staining at 24 hours. PDGF- $\beta$ and PDGF- $\beta$ receptor staining correlated as expected (Fig. 10). Negative and positive controls stained accordingly. Antigen-excess experiments abolished staining in MC, as expected. Avidinbiotin blocking experiments further assured the specificity of the staining in MC for PDGF- $\beta$, PDGF- $\beta$ receptor, and TGF- $\beta$.

\section{Discussion}

MC play a pivotal role in the propagation and progression of tissue injury in monoclonal light chain-related glomerulopathies (Herrera et al, 1999) and other glo- 


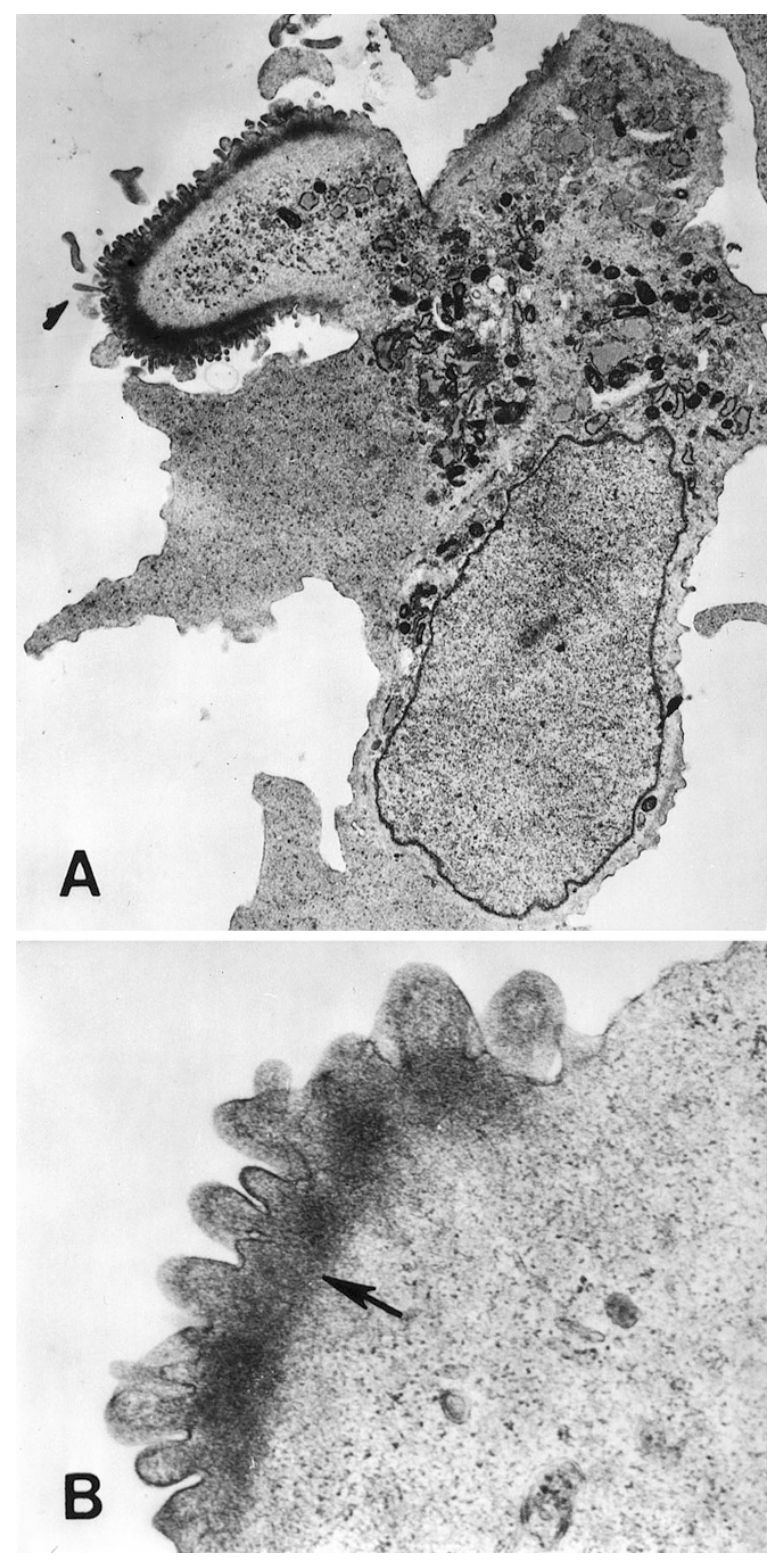

Figure 6.

Transmission electron microscopy; uranyl acetate and lead citrate. The circumferential MC ruffling becomes localized to specific surface areas approximately 60 to 90 minutes after exposure of MC to G-LC. Underneath the focal areas of ruffling, actin accumulation occurs (arrow). Original magnification, $A, \times 7,500 ; B, \times 10,500$.

merular diseases (Abboud, 1991). LC-MC interactions are crucial in the pathogenesis of monoclonal LCrelated renal diseases. The binding of the LCDD-LC to $\mathrm{HMC}$ at room temperature and $\mathrm{pH} 7.4$, although in small quantities, emphasized the MC surface interactions that occur with this type of G-LC. Actin reorganization and surface ruffling was noted in approximately $20 \%$ and $10 \%$ of MC incubated with G-LC, either LCDD or AL-LC, respectively, whereas similar alterations were not seen in MC incubated with albumin, emphasizing that interactions between LC and MC take place. In contrast, T-LC induced ruffling in less than $1 \%$ of the MC. In previous work using immunoelectron microscopic techniques, LCDD-LC were shown to be intimately associated with the MC surface and localized to areas in the MC membrane ultrastructurally resembling clathrin-coated pits (Zhu et al, 1995). Internalization of the LCDD-LC was followed by rapid lysosomal degradation.

In contrast, no surface interactions could be detected when AL-LC were incubated with $\mathrm{MC}$ at room temperature or at $37^{\circ} \mathrm{C}$ and $\mathrm{pH} 7.4$. It seemed plausible to theorize that if AL-LC were internalized, a clathrin-mediated process might be involved. To test this, LC were incubated with HMC under a variety of conditions $\left(4^{\circ} \mathrm{C}\right.$, hypertonic medium, acidified medium) to disrupt clathrin-mediated internalization. Of these approaches, the acidification of the medium to $\mathrm{pH} 5.0$ resulted in the largest increase in the percentage of the gated population to which LC was bound.

The increase in binding to HMC was observed only for those LC that were glomerulopathic, the LCDD-LC (at room temperature and $37^{\circ} \mathrm{C}, \mathrm{pH} 7.4$ ) and the AL-LC (under acidified pH 5 conditions), and that are known to interact with HMC in vivo and in vitro. The acidification of the medium to $\mathrm{pH} 5.0$ did not increase the binding of the myeloma cast nephropathy T-LC. The relative specificity of the binding of G-LC to HMC under acidified conditions is reflected in the inability of the $\mathrm{AL}-\mathrm{LC}$ to bind to $\mathrm{CHO}$ cells and the small binding of the Hac (AL)-LC to $L$ cells, a mouse fibroblast cell line. The binding of $\mathrm{Hac}$ to $\mathrm{L}$ cells probably is related to the similar mesodermal derivation of these two cell types. MC are modified smooth muscle cells and these two cell lines may share a common receptor.

The exact identity of the putative HMC-LC receptor is under investigation and currently is unknown. Receptors for immune complexes have been described on MC (López-Armada et al, 1996) enabling them to phagocytose immune complexes. The fact that shortterm (signaling) events occur as LC interact with MC, such as the cytosolic to nuclear relocalization of signaling molecules (c-fos and NF- $\kappa \beta$ ), further supports the existence of a receptor-mediated mechanism as part of these G-LC-MC interactions. Batuman and colleagues have identified cubilin as a highcapacity, low-affinity receptor for LC that can mediate their endocytosis in renal proximal tubule cells (Batuman and Guan, 1997; Batuman et al, 1998). This protein belongs to the low-density lipoprotein (LDL) family of receptors. A common feature of this family of receptors is the ability to function as a multiligand receptor and bind multiple ligands with varying affinities at different sites. Cubilin contains at least 35 potential binding domains and, in addition to LC, is also capable of binding lysozyme, insulin, cytochrome $\mathrm{c}$, myoglobin, and $\beta_{2}$-microglobulin. Whether cubilin is expressed by HMC is unknown. Although cubilin represents the predominant receptor for LC on proximal tubule cells, other receptors may be present as well. The pattern of increased mesangial matrix components similar to that observed in diabetic nephropathy suggests that certain LC could bind to MC via the receptor for advanced glycosylation end-products (AGE). Yan et al (2000) have shown that RAGE (receptor for advanced glycosylation end-products) is a 


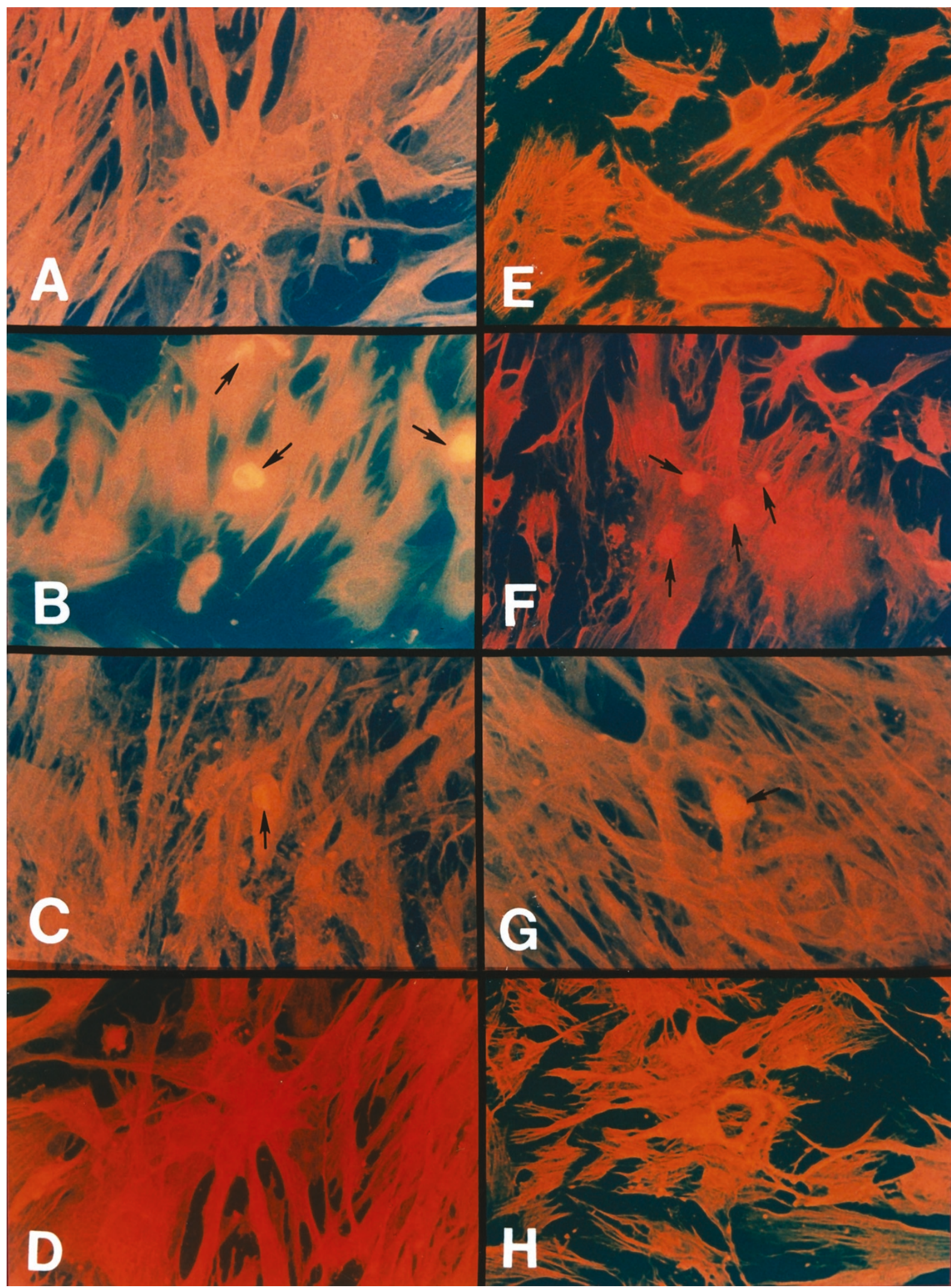

\section{Figure 7.}

A to $\mathrm{H}$, Fluorescence Texas red. Left panels, c-fos; Right panels, FN- $\kappa \beta$ staining. A and E, Unstimulated MC with cytoplasmic distribution of NF- $\kappa$ (left) and $\mathrm{c}$-fos (right). On exposure to LCDD-LC, NF- $\kappa \beta$ and $\mathrm{c}$-fos become redistributed from cytoplasm to nuclei (B and F). Likewise, on exposure to AL-LC a similar redistribution of NF- $\kappa \beta$ and $\mathrm{C}$-fos was noted; however, the number of MC showing redistribution is significantly less (C and G). When HMC was exposed to T-LC, the NF- $\kappa \beta$ and $c$-fos remained in a cytoplasmic location and did not migrate to the nuclei (D and $H)$. Note that MC with nuclear $c$-fos expression appear rounded and show surface ruffling. Original magnification, $\times 350$. 


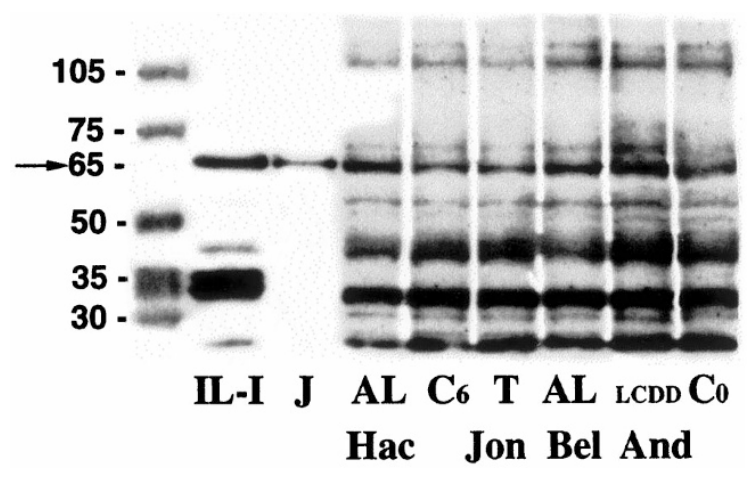

Figure 8.

NF- $\kappa \beta$ detection in nuclear preparations of MC at baseline (C0), 6 hours (C6), after exposure to IL-1 and a Jurkat cell lysate as positive controls (6 hours), and on exposure to two AL-LC (Hac and Bel), a LCDD-LC (And), and a T-LC (Jon) at 6 hours. Note that the LCDD-LC shows the most intense band (similar to that of IL-1) followed by AL-LC (HaC and Bel). T-LC band is about the same intensity as control MC at the same time frame (6 hours) indicated as C6.

receptor for the amyloidogenic form of serum amyloid $A$ in a mononuclear phagocytic cell line. This hypothesis is supported by the fact that approximately $20 \%$ to $30 \%$ of LC isolated from patients with monoclonal LC-related renal diseases are glycosylated. The activation of the yet-uncharacterized receptor in $\mathrm{MC}$ results in increased ECM via long-term events resulting from PDGF- $\beta$ activation followed by TGF- $\beta$ production following a pattern of growth factor activation similar to that that has been seen in the in vitro model of LCDD-LC-mediated mesangial injury (Herrera et al, 1999). Similarly, in biopsy specimens, expression of these two growth factors has also been documented (Herrera et al, 1994). It is unclear at present whether the putative receptors for $\mathrm{LC}$ on $\mathrm{MC}$ are specific or shared by other effector molecules. Likewise, it is unknown whether LCDD and AL-LC use the same or a different receptor.

The lack of effect for T-LC on mesangial matrix homeostasis is consistent with studies examining the binding of T-LC to proximal tubule cells. Batuman and colleagues used a pH 5.0 isotonic saline solution to remove membrane-bound T-LC (Batuman et al, 1998). Thus, an inherent difference appears to exist in the (affinity) ability of G- and T-LC to bind to HMC, and this difference most likely reflects amino acid differences within the variable region of individual LC. The ability of certain LC to interact differently with target cells underscores their selective pathogenic potential for specific nephron sites and thus provides an explanation for their glomerulopathic versus tubulopathic properties.

The present study also highlights the importance of internalization in the pathogenesis of amyloidogenesis. Only when internalization is blocked can the AL-LC be demonstrated on the MC surface, emphasizing that the delivery of AL-LC to intracellular compartments for processing is a crucial component in their pathogenesis. In contrast, the surface interactions play a key role in the case of LCDD-LC, resulting in the binding of these $\mathrm{LC}$ to putative $\mathrm{MC}$ receptors to trigger intracellular events that lead to increased tran- scription of matrix protein genes. Kon and colleagues have demonstrated a functional interaction between two early-intermediate transcription factors, NF- $\kappa \beta$ and SMAD, to activate the expression of an ECMrelated gene, COL7A1 (Kon et al 1999). It can be hypothesized from this data that a similar combined effect involving NF- $\kappa \beta$ and TGF- $\beta$ through SMAD may regulate the expression of other ECM-related genes in LCDD, accounting for the increase in ECM that is characteristic of this condition (Kon et al, 1999; Lawrence, 1995; Poncelet and Schnaper, 1998; Sharma and Ziyadeh, 1993; Whitman, 1998). In AL-Am, the accentuated MMP effect on the ECM, perhaps a direct effect of the amyloid deposition, predominates, resulting in a decrease in ECM. Amyloid may also exert a negative feedback on long-term effects.

It was demonstrated in the present study that signaling mechanisms are activated when LCDD-LC contact $\mathrm{MC}$. NF- $\kappa \beta$ and $\mathrm{c}$-fos migrate quickly (within minutes) from their normal cytoplasmic location to assume nuclear expression as a crucial component of the signaling cascade. MCP-1 production by HMC when exposed to G-LC occurs concomitantly. There was no effect on TNF- $\alpha$ production by MC when stimulated with the different LC. NF- $\kappa \beta$ is found normally in the cytoplasm of $\mathrm{MC}$ as a dimer of p50 and p65 subunits bound to the inhibitory protein $I_{\kappa} \beta$. On stimulation of $\mathrm{MC}$ by $\mathrm{LC}, \mathrm{I} \kappa \beta$ is released from the dimer, resulting in migration of the p50-p65 complex to the nucleus and subsequent DNA binding. Although migration of $\mathrm{c}$-fos and NF-k $\beta$ also occurred when AL-LC interacted with HMC, this signaling pathway was not as effective as in the case of LCDD-LC-MC interactions. The degree of activation of NF- $\kappa \beta$ in the different experimental conditions correlated directly with the level of production of MCP-1 by HMC. Furthermore, the kinetics of NF- $\kappa \beta$ activation correlates with MCP-1 production by MC. Translocation to the nucleus of active NF- $\kappa \beta$ and binding to specific DNA sequences on NF- $\kappa \beta$ response genes, such as MCP-1, RANTES, and ICAM-1, can lead to their enhanced transcription and generation. Analysis of the promoter region of human MCP-1 has demonstrated several putative binding sites for transcriptionactivating factors, including recognition elements for $\mathrm{NF}-\kappa \beta$. NF $-\kappa \beta$ activation appears to be a necessary requirement for chemokine induction. It is interesting that the effect of AL-LC on NF- $\kappa \beta$ is not as marked as in the case of LCDD-LC, perhaps an additional indication of divergent mechanisms at play in LCDD and AL-Am. Although activation of NF- $\kappa \beta$ plays a central role in MC signaling activation (Massy et al, 1999), it is not clear if key downstream events, such as TGF- $\beta$ production by $\mathrm{MC}$ leading to progressive renal damage (Kopp et al, 1996; Zhu et al, 1995), are also controlled directly by NF- $\kappa \beta$ activation. NF- $\kappa \beta$ could be stimulated through a phosphotyrosine kinase signaling mechanism as proposed by Rovin et al (1995); however, this is not accepted universally (Kopp et al, 1996). The reduction in Ki-67 expression in HMC pretreated with anti-c-fos antibody before incubation with G-LC, especially LCDD-LC, suggests that c-fos 
Table 1. MCP-1 Concentrations in Supernatant of HMCs Incubated with and without LCs

\begin{tabular}{cccccc}
\hline $\begin{array}{c}\text { Post-application } \\
\text { time frame }(\mathrm{h})\end{array}$ & $\begin{array}{c}\text { Media } \\
\text { alone }\end{array}$ & T-LC & AL-LC & LCDD-LC & $\begin{array}{c}1 \mathrm{~L}-1 \\
\text { control }\end{array}$ \\
\hline 3 & 1767 & 1571 & 1604 & 2150 & 9912 \\
6 & & 1961 & 3943 & 4264 & 6547 \\
12 & 2683 & 2885 & 5251 & 6 \\
\hline
\end{tabular}

MCP-1, monocyte chemoattractant protein-1; HMCs, human mesangial cells; LCs, light chains; T-LC, tubulopathic light chain; AL-LC, amyloidogenic light chain; LCDD-LC, light chain deposition disease light chain; IL-1, interleukin-1.

Table 2. Percentage of Ki-67 Staining in HMCs Incubated with and without LCs and PDGF-BB

\begin{tabular}{cccccc}
\hline & Media & & & \multicolumn{2}{c}{ PDGF-BB } \\
Time (h) & No LC & LCDD-LC & AL-LC & T-LC & No LC \\
\hline 1 & 10.5 & 16.7 & 14 & 9.8 & 28 \\
3 & 12 & 20.5 & 17 & 10 & 30 \\
6 & 15 & 22 & 18 & 11 & 33 \\
24 & 17 & 25 & 22 & 13 & 34 \\
\hline
\end{tabular}

PDGF-BB, platelet-derived growth factor-BB.

Table 3. Percentage of Ki-67 Staining in HMCs with and without Pretreatment with Anti-c-fos before Incubation with LCs and PDGF- $\beta$

\begin{tabular}{ccccccc}
\hline \multirow{2}{*}{ Time $(\mathrm{h})$} & & Media & & & & \multicolumn{2}{c}{ PDGF-BB } \\
& & No LC & LCDD-LC & AL-LC & T-LC & No LC \\
\hline \multirow{2}{*}{6} & - c-fos & 14 & 20 & 19 & 13 & 30 \\
& + c-fos & 12 & 8 & 17 & 12 & 19 \\
& - c-fos & 17 & 22 & 20 & 15 & 34 \\
& + c-fos & 18 & 11 & 16 & 14 & 19 \\
\hline
\end{tabular}

signaling may be important in regulating the PDGF- $\beta$ driven mitogenic stimuli in HMC. Furthermore, c-fos likely mediates cytoskeletal rearrangement in $\mathrm{MC}$ through PDGF- $\beta$ activation. Induction of membrane ruffling on human fibroblasts by PDGF has been documented previously (Mellström et al, 1988).

Further characterization of these receptor-mediated interactions has the potential to lead to a conceptual framework capable of serving as a basis for designing new therapeutic interventions. Currently, the therapeutic armamentarium available to treat these monoclonal LC-related renal disorders is limited to treating the clone of neoplastic plasma cells responsible for the production of the pathogenic LC. Progression to renal failure is the rule in these conditions since even small amounts of certain G-LC may result in continued renal damage that eventually becomes irreversible. Interventions aimed at crucial events responsible for the pathogenic effects of G-LC on glomeruli must be designed to prevent irreversible renal damage. Regulating NF- $\kappa \beta$ activation may prove of value in preventing $\mathrm{MC}$ activation and early cytokine production, as has been suggested by some in vitro studies (Auwardt et al, 1998; Ishikawa et al 1999). Likewise, TGF- $\beta$ could be a target for therapeutic intervention in LCDD (Auwardt et al, 1998; Border et al, 1992; Böttinger et al, 1997; Feige and Baird, 1995; Ishikawa et al, 1999; Lipkowitz et al, 1996; Peters et al, 1998; Satriano and Schlondorff, 1994). In contrast, activation of c-fos appears to play a crucial role in the generation of proliferative/mitogenic and cytoskeletal signals in MC.

\section{Conclusions}

Signaling mechanisms mediated through $\mathrm{NF}-\kappa \beta$ and C-fos are responsible for short-term effects of G-LC on $\mathrm{HMC}$ resulting in the production of MCP-1 and cellular proliferation and cytoskeletal rearrangement, respectively. Interruption of these short-term effects may or may not result in subsequent alterations of the longterm phenomena responsible for the pathologic alterations that occur in glomeruli of patients with LCDD or AL-Am. Understanding the intricacies of the mechanisms involved in LC-MC interactions may be important to identify potential targets for selective therapeutic intervention through modulation or complete abrogation of specific pathways involved in glomerular injury.

\section{Materials and Methods}

\section{LC Purification from Urine}

The immunoglobulin LC used in this study were purified by affinity chromatography from the urine of patients with renal biopsy-proven myeloma cast nephropathy (T-LC), LCDD, or AL-Am (G-LC). In essence, immunoglobulin LC were purified from the urine in standard fashion using ammonium surface 


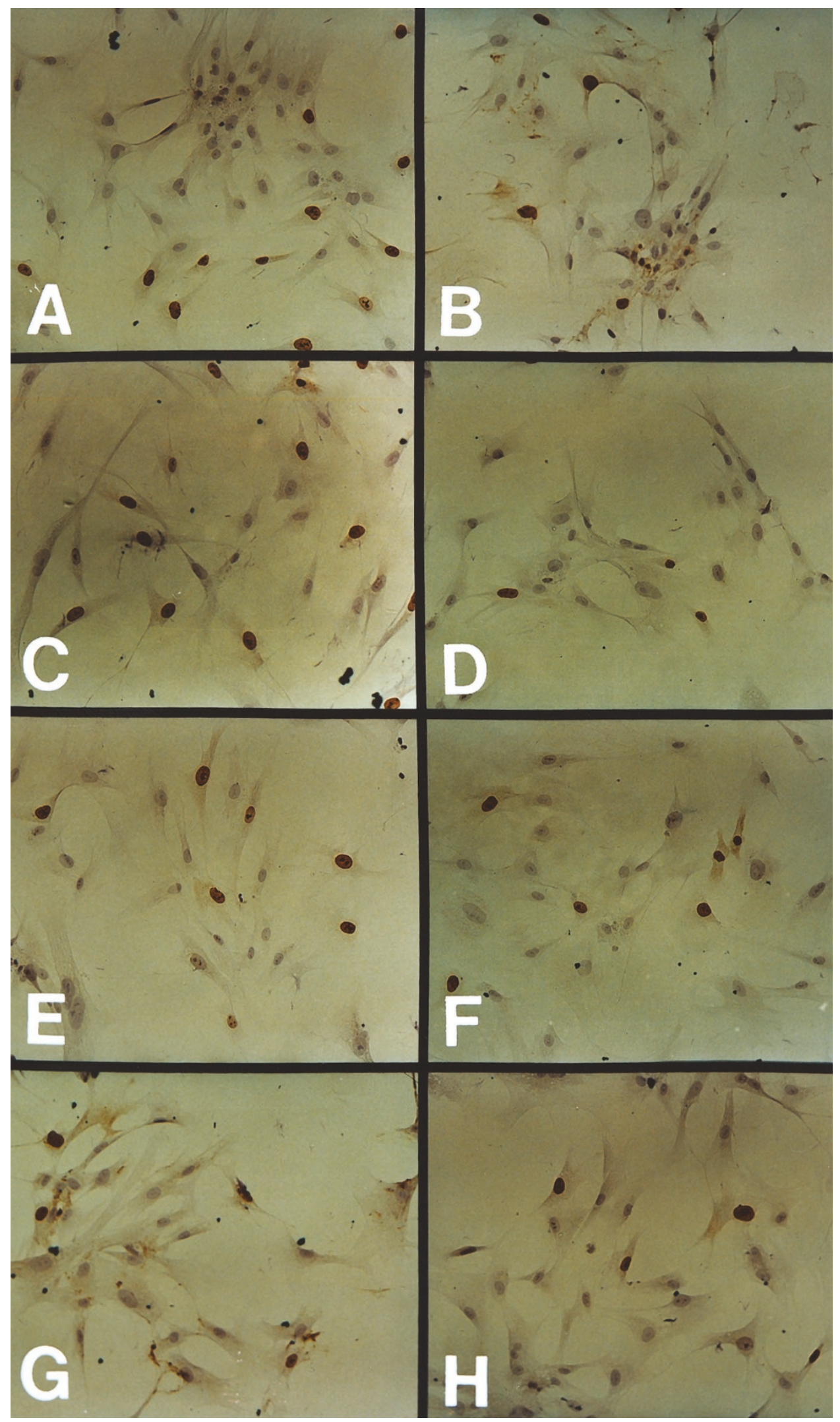

\section{Figure 9.}

Ki-67 staining of MC with (right panel) and without (left panel) preincubation with anti-c-fos and subsequently incubated with various LC and PDGF-BB as indicated $A$ and B, Incubated with LCDD-LC; $C$ and D, incubated with PDGF-BB; E and F, incubated with AL-LC; and G and H, incubated with T-LC. Note, by comparing A, B, $C$, and D (LCDD- and PDGF-BB-treated cells), that c-fos preincubation reduced by approximately half the number of Ki-67 positive cells. The difference between $E$ and $\mathrm{F}(\mathrm{AL}-\mathrm{LC})$ is not as noticeable. In contrast, the number of Ki-67-positive cells is rather small in $\mathrm{G}$ and $\mathrm{H}$, corresponding to MC treated with T-LC. Original magnification, $\times 160$ 


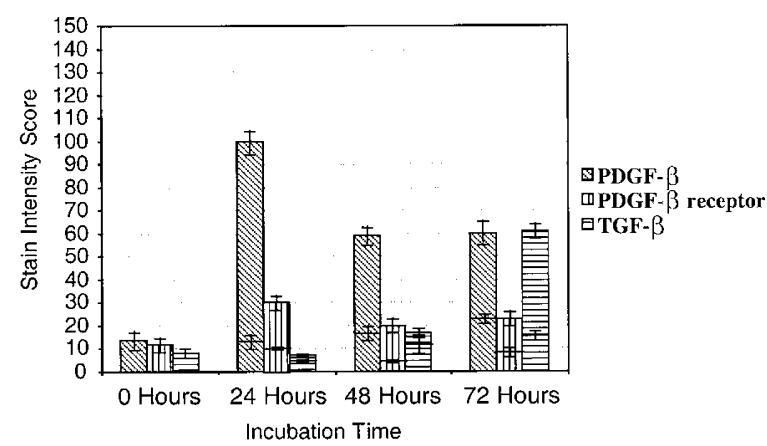

Figure 10.

PDGF- $\beta$, PDGF- $\beta$ receptor, and TGF- $\beta$ staining in HMC incubated with LCDD-LC and media alone (baseline). PDGF- $\beta$ and its corresponding receptor staining peaked at 24 hours post-incubation, highlighting the early activation of this growth factor when MCs are exposed to G-LC. Note also that TGF- $\beta$ staining peaked late at 72 hours post-incubation of MCs with G-LCs.

precipitation and ion exchange, as described previously (Sanders et al, 1987). Affinity chromatography consisted of passing urine over Sepharose CL-4B columns to which either goat antihuman $\lambda$ or antihuman $\kappa$ antibodies had been conjugated. Free plus bound $\lambda$ or $\kappa$ LC were eluted from the columns with $0.1 \mathrm{M}$ glycine, $\mathrm{pH}$ 2.2. The purity of the LC was checked on immunodiffusion plates and anti-lgG and anti-lgA affinity columns were used to remove contaminating $\operatorname{lgG}$ and $\lg A$. When purified, the LC migrates as a single band when resolved by zone electrophoresis on agarose gels using a $50 \mathrm{~mm}$ barbital buffer, $\mathrm{pH} 8.6$, and consists entirely of either free $\lambda$ or $\kappa$ LC as determined by immunofixation. Purified LC were concentrated, dialyzed against $0.9 \% \mathrm{NaCl}$, filtered through a 0.2-m membrane, and stored aseptically at $1 \mathrm{mg} / \mathrm{ml}$ at $4^{\circ} \mathrm{C}$. The following nephrotoxic $\mathrm{LC}$ were purified: And, a $\kappa$ LCDD-LC; Mat, a $\kappa$ AL-LC; Hac and Bel, two $\lambda$ AL-LC; and Jon, a $\lambda$ T-LC from a patient with myeloma cast nephropathy. The purified LC had the same composition as those circulating in the serum. The LC proteins were selected to highlight that LC class does not necessarily dictate effects resulting from LC-MC interactions. Furthermore, due to limited availability, not all LC were used in all experiments. The LC employed in the various experiments were carefully chosen, depending on the question to be addressed.

\section{Testing of Purified LC for Endotoxins}

All LC preparations were tested for endotoxins using the Limulus amebocyte assay (Charles River Endosafe, Charleston, South Carolina). Briefly, endotoxin content is semiquantitated by mixing a kit reagent (amebocyte lysate) with test sample or endotoxin standards and observing for gelation after incubation for 60 minutes at $37^{\circ} \mathrm{C}$. If gelation occurs, it indicates that there is an amount of endotoxin in the sample that equals or exceeds the reagent's labeled sensitivity (0.125 EU/ml, a negligible amount). Appropriate positive controls with a 0.125 to $100 \mathrm{EU} / \mathrm{ml}$ range were also tested concomitantly, as well as negative controls with a 0.015 to $0.0625 \mathrm{EU} / \mathrm{ml}$ range. An additional negative water control and positive product control spiked with $2 \lambda$ CSE were also tested.

\section{HMC Culture}

Primary cultures of adult HMC isolated as out-growths from glomerular remnants were obtained from nephrectomy specimens following Harper's methodology (Harper et al, 1984). Briefly, the renal cortex from uninvolved areas of kidneys removed for renal cell carcinoma was cut into a fine mince (approximately 1-mm cubes). This mince was successively passed over stainless steel meshes of 300, 250, and $150 \mu \mathrm{m}$ pore size. Glomeruli retained by the $150-\mu \mathrm{m}$ mesh were incubated for 30 minutes at room temperature with occasional agitation in $\mathrm{Ca}^{+2} / \mathrm{Mg}^{+2}$ containing HBSS to which was added $750 \mathrm{U} / \mathrm{ml}$ collagenase. Following the collagenase digestion, glomeruli were allowed to settle out, the supernatant was removed, and the glomeruli resuspended in fresh HBSS. This rinse step was repeated twice. The clean glomerular sediment obtained was resuspended in RPMI 1640 medium at $37^{\circ} \mathrm{C}$ and buffered with $25 \mathrm{~mm}$ HEPES at pH 7.4 and supplemented with 20\% FBS, $100 \mathrm{U} / \mathrm{ml}$ penicillin, $100 \mu \mathrm{g} / \mathrm{ml}$ streptomycin, $5 \mu \mathrm{g} / \mathrm{ml}$ bovine insulin, $5 \mu \mathrm{g} / \mathrm{ml}$ transferrin, $5 \mathrm{ng} / \mathrm{ml}$ sodium selenite, $0.4 \mu \mathrm{g} / \mathrm{ml}$ hydrocortisone, $2 \mathrm{~mm}$ glutamine, and $1 \mathrm{~mm}$ sodium pyruvate. Glomerular remnants and $\mathrm{HMC}$ isolated from them were continuously cultured at $37^{\circ} \mathrm{C}$, $5 \% \mathrm{CO}_{2}$, and $92 \%$ relative humidity. The glomeruli were plated out on $100-\mathrm{mm}^{2}$ plates. After 7 days, outgrowths of $\mathrm{MC}$ from the glomerular remnant were detected and by 21 days the MC had begun to overgrow the epithelial cell contaminant. The MC were serially passaged four times to ensure a homogenous population. These cells were determined to be a homogenous population of MC based on immunocytochemistry and ultrastructural evaluation. HMC were negative for cytokeratin, CD45 (common leukocyte antigen), and Factor VIII antigens, but expressed smooth muscle actin and vimentin. These immunocytochemical reactions characterized the cells as MC and not epithelial, endothelial, or monocytic cells. Ultrastructurally, the cells showed myofilaments with spindle densities and attachment plaques indicating their smooth muscle characteristics. Passage 5 to 6 $\mathrm{HMC}$ grown to confluence in $25-\mathrm{mm}^{2}$ flasks using high serum RPMI were used in this study. Two days before use in the experimental studies, the FBS content of the medium was reduced to $0.5 \%$ to render the cells quiescent.

\section{Binding Studies}

Monoclonal LC purified from the urine of patients with myeloma cast nephropathy (T-LC, Jon), LCDD (And), and $\mathrm{AL}-\mathrm{Am}$ ( $\mathrm{Hac}$ and $\mathrm{Bel}$ ) were added to low serum (0.5\% FBS) RPMI at $10 \mathrm{mg} / \mathrm{ml}$. These LC were individually added to quiescent adult $\mathrm{HMC}$ in $25-\mathrm{mm}^{2}$ flasks and LC binding was assessed at $25^{\circ} \mathrm{C}, 37^{\circ} \mathrm{C}$, and $4^{\circ} \mathrm{C}$, and again at $25^{\circ} \mathrm{C}$ and $37^{\circ} \mathrm{C}$ after the 
medium was made acidic ( $\mathrm{pH} 5.0)$ or hypertonic with the addition of acetic acid (10 mm) or sucrose $(0.45 \mathrm{~m})$ to the medium. After a 30-minute incubation under these conditions, the flasks were quickly rinsed three times under the same conditions and with the same medium as in the initial incubation to remove unbound LC. LC binding to HMC was detected by adding either goat $\mathrm{F}\left(\mathrm{ab} \mathrm{b}_{2}\right)_{2}$ antihuman (R-PE conjugate), or $\kappa$ (FITC conjugate) antibodies to the same low serum RPMI medium as before (normal, acidic, or hypertonic) and incubating with $\mathrm{HMC}$ at the same temperature as before $\left(25^{\circ} \mathrm{C}\right.$ or $\left.4^{\circ} \mathrm{C}\right)$ for an additional 15 minutes in the absence of LC. The flasks were then rinsed twice with cold FACS buffer ( $2 \% \mathrm{FBS}, 0.1 \% \mathrm{NaN}_{3}$ in PBS) to remove excess antibody. Cold glass beads and FACS buffer $(2 \mathrm{ml})$ were added to each flask and the HMC were removed from the flask with gentle agitation by rolling the glass beads around the flasks at $4^{\circ} \mathrm{C}$. Visual examination of the flasks using a phase contrast microscope revealed nearly complete harvesting of $\mathrm{MC}$ attached to the flasks. The HMC cell suspension obtained was centrifuged at $1,000 \mathrm{rpm}$ for 10 minutes at $4^{\circ} \mathrm{C}$. The $\mathrm{HMC}$ cell pellet was resuspended in $130 \mathrm{ml}$ of FACS buffer and $150 \mathrm{ml}$ of $2 \%$ formaldehyde in PBS and fixed on ice for 15 minutes. The fixed cells were centrifuged as before and resuspended in 1 ml FACS buffer. After a final centrifugation, the cell pellet was resuspended in $300 \mathrm{ml}$ of FACS buffer and placed on ice until LC binding to the HMC was assessed as membrane fluorescence with a FACS Vantage cytometer. In another series of experiments LC binding to fetal HMC (Clonetics, San Diego, California), mouse fibroblasts, L, and Chinese hamster ovary epithelial cells was examined under normal $(\mathrm{pH}$ 7.4) and acidified ( $\mathrm{pH} \mathrm{5.0)}$ conditions as previously described for adult HMC.

\section{Direct Fluorescence Microscopy}

Direct fluorescence staining following standard procedures (Valenzuela and Deodhar, 1986) and using Texas red-phalloidin to study MC cytoskeletal F-actin distribution was performed to identify if surface or cytoskeletal actin alterations occurred associated with incubation of MC with $\mathrm{G}$ and T-LC.

$\mathrm{MC}$ grown on glass cover slips or chambered glass slides were first fixed at room temperature for 5 minutes with $20 \%$ formaldehyde in PBS and then further fixed/permeabilized at $-20^{\circ} \mathrm{C}$ for 5 minutes with methanol containing $1 \%$ formaldehyde. A similar fixation protocol was used before staining mesangial cells for $\mathrm{Ki}-67$, c-fos, NK- $\kappa \beta$, PDGF- $\beta$, PDGF- $\beta$ receptor, and TGF- $\beta$. MC incubated either without or with $\mathrm{AL}$ and LCDD-G and T-LC (10 $\mathrm{ug} / \mathrm{ml})$ were stained with Texas red-phalloidin (Molecular Probes, Eugene, Oregon) using a direct fluorescence method. Control MC were only incubated with albumin and no LC. MC were then analyzed using fluorescence microscopy with an Olympus BX60 fluorescence microscope (C. Squared Company, Tamarac, Florida) to identify whether changes in the distribution of actin within the cytoskeleton and/or surface ruffling were present.

\section{Ultrastructural Evaluation}

Specimens for ultrastructural evaluation were fixed in Carson-Millonig solution (Polysciences, Warrington, Pennsylvania), embedded in epoxy resin (Polysciences), and thick sectioned for light microscopic survey. The specimens included MC incubated with albumin as control, LCDD, AL, and T-LC. Toluidine blue-stained sections were used to select areas for preparation of thin sections. Once appropriate areas were identified, thin sections for ultrastructural evaluation were prepared. Thin sections were stained with uranyl acetate and lead citrate (Fisher Scientific, Pittsburgh, Pennsylvania). The specimens were examined with a Philips CM 10 transmission electron microscope (N.V. Philips, Eindhoven, The Netherlands). The percentage of MC with surface ruffling was calculated.

\section{Immunolocalization of $c$-fos and NF-к $\beta$ p65 in LC-Treated and Untreated HMC}

HMC grown on 18-mm coverslips and fixed as detailed previously were incubated with $10 \mu \mathrm{g} / \mathrm{ml}$ of various LC (And-LCDD-LC, Mat, Bel-AL-LC, or Jon T-LC) in low serum (0.5\% FBS) RPMI 1640 for 20 minutes. $\mathrm{MC}$ in medium alone served as a negative control. After 20 minutes, the cells were fixed at room temperature for 5 minutes with $2 \%$ formaldehyde in PBS. The cells were then permeabilized at $-20^{\circ} \mathrm{C}$ for 5 minutes with methanol containing $1 \%$ formaldehyde. The cellular distribution of c-fos and NF- $\kappa \beta$ p65 (cytosolic versus nuclear) was then assessed by immunofluorescence. HMC were incubated with a 10fold dilution of rabbit polyclonal antibody to either c-fos (sc-52; Santa Cruz Biochemicals, Santa Cruz, California) or human NF- $\kappa \beta$ p65 (sc-109, Santa Cruz) for another 1 hour at room temperature. The antibodies were diluted into PBS containing $0.25 \%$ BSA and $0.1 \%$ saponin before $300 \mu$ l of diluted antibody solution was added to each coverslip. A 200 -fold dilution of a Texas red conjugated goat antirabbit polyclonal antibody (Jackson ImmunoResearch, West Grove, Pennsylvania) was used to detect the distribution of the corresponding antigenic determinants detected within the MC. After 1 hour incubation at room temperature, the secondary antibody was rinsed off, the coverslips mounted on glass slides, and the cellular distribution in $\mathrm{HMC}$ of $\mathrm{c}-\mathrm{fos}$ and $\mathrm{NF}-\kappa \beta$ visualized with an Olympus BX60 fluorescence microscope.

\section{Western Analysis of Nuclear Protein Extracts for NF-к及 65p in HMC}

And (LCDD-), Bel (AL-), Hac (AL-), and Jon (T)-LC (10 $\mu \mathrm{g} / \mathrm{ml})$ were added to confluent HMC growing in $100-\mathrm{mm}$ dishes. HMC in medium alone or to which 10 $\mu \mathrm{g} / \mathrm{ml}$ BSA was added served as negative controls. After $0.5,1,2,4,6$, and 12 hours, the HMC were trypsinized and a nuclear protein extract was obtained as described by Schreiber et al (1989). Briefly, trypsinized HMC were pelleted, resuspended in $500 \mu \mathrm{l}$ of hypotonic buffer A (10 mM HEPES, pH 7.9, 10 mm 
$\mathrm{KCl}, 0.1 \mathrm{~mm}$ EDTA, 0.1 mm EGTA, $1 \mathrm{~mm}$ DTT, and 0.5 mM PMSF) and allowed to swell on ice for 15 minutes. Ten percent Nonidet NP-40 was then added to buffer A to a final concentration of $0.5 \%$ and the cells were lysed by vortexing for 10 seconds. After centrifuging the lysate for 30 seconds in a centrifuge at $12,000 \times g$, a nuclear pellet was obtained that was extracted for protein by vortexing the pellet with $50 \mu \mathrm{l}$ of high salt buffer B (20 mm HEPES, pH 7.9, 400 mm NaCl, 1 mm EDTA, $1 \mathrm{~mm}$ EGTA, $1 \mathrm{~mm}$ DTT, $1 \mathrm{~mm}$ PMSF) for 15 minutes at $4^{\circ} \mathrm{C}$. Insoluble nuclear debris was then pelleted by centrifugation at $12,000 \times g$ in a microfuge for 5 minutes and the supernatant containing extracted nuclear proteins was carefully removed. The protein content of the extracts was determined by the BCA assay (Pierce, Rockford, Illinois). Twenty micrograms of total protein per well were loaded for each sample and the nuclear proteins resolved by SDSPAGE on $3 \%$ to $8 \%$ polyacrylamide gels (Novex, San Diego, California) at 200v for 50 minutes using an SDS tris-acetate buffer. The resolved proteins were then transferred electrophoretically to PVDF membranes at $10 \mathrm{v}$ for 3 hours. The PVDF membranes were blocked with $1 \mathrm{mg} / \mathrm{ml}$ BSA in TBS containing 0.1\% Tween-20 (blocking buffer). The membranes were analyzed for NF- $\kappa \beta$ content using $0.5 \mu \mathrm{g} / \mathrm{ml}$ of a mouse anti-NF- $\kappa \beta$ monoclonal antibody to human NF- $\kappa \beta$ p 65 as primary antibody, a horseradish peroxidase conjugated goat antirabbit polyclonal antibody, 1:100,000 dilution (Jackson ImmunoResearch) as the secondary antibody, and Pierce's SuperSignal West Dura Extended Duration chemiluminescent substrate. A Jurkat $(\mathrm{J})$ cell lysate and IL-1 were used as positive controls for detection of NF- $\kappa \beta$ p 65 .

\section{MCP-1 Measurements in HMC}

ELISA plates (Costar, Cambridge, Massachusetts) were coated with $100 \mu \mathrm{l}$ of monoclonal antibody to human MCP-1 (3.3 $\mu \mathrm{g} / \mathrm{ml}$; Endogen, Woburn, Massachusetts) in $0.1 \mathrm{~mm}$ sodium carbonate buffer ( $\mathrm{pH}$ 9.6) and incubated overnight at $4^{\circ} \mathrm{C}$. After coating, the ELISA plates were washed once (4 minutes) with 200 $\mu$ l of PBS containing $0.05 \%$ Tween 20 (wash buffer). All subsequent washes were performed similarly. The plates were then blocked using $200 \mu$ l PBS-Tween 20 containing 3\% (w/v) BSA (Sigma Chemical, St. Louis, Missouri) as a blocking buffer for 2 hours at room temperature. After blocking, the plates were washed three times before use. All subsequent steps were performed in blocking buffer. One hundred microliters of diluted conditioned media from experimental samples (diluted at least 1:20 in blocking buffer) or standards $(7.8-500 \mathrm{pg} / \mathrm{ml})$ was incubated overnight at $4^{\circ} \mathrm{C}$. Plates were washed four times and incubated with $100 \mu \mathrm{l}$ of biotinylated polyclonal antibody to MCP-1 (500 ng/ml; Pharmingen, San Diego, California) for 2 hours at room temperature. Plates were washed three times and then incubated with streptavidinghorseradish peroxidase (1:5,000; Poly-Strep-HRP, Endogen, Woburn, Massachusetts) for 30 minutes at room temperature. After washing, $100 \mu \mathrm{l}$ TMB substrate (Bio-Rad, Hercules, California) was added and incubated for 15 minutes. The reaction was stopped with $100 \mu \mathrm{l}$ of $0.1 \mathrm{~N}$ sulfuric acid and read at $450 \mathrm{~nm}$ using an ELISA plate reader (Cayman Chemical, Ann Arbor, Michigan).

\section{TNF- $\alpha$ Measurements in HMC}

ELISA plates (CoStar) were coated with $100 \mu$ of monoclonal antibody to human TNF $\alpha(3.5 \mu \mathrm{g} / \mathrm{ml}$; Endogen) to $10 \mathrm{~mm}$ PBS ( $\mathrm{pH} 7.4)$ and incubated overnight at $4^{\circ} \mathrm{C}$. After coating, the ELISA plates were washed once (4 minutes) with $200 \mu$ l PBS containing $0.05 \%$ Tween 20 (wash buffer). All subsequent washes were performed similarly. The plates were then blocked using $200 \mu$ l PBS-Tween 20 containing $3 \%(\mathrm{w} / \mathrm{v})$ BSA (Sigma Chemical) as a blocking buffer for 2 hours at room temperature. After blocking, the plates were washed three times before use. All subsequent steps were performed in blocking buffer. One hundred microliters of diluted conditioned media (diluted 1:5 in blocking buffer) from experimental samples or standards (3.9 to $500 \mathrm{pg} / \mathrm{ml}$ ) was incubated for 1 hour at room temperature. After incubation, $50 \mu$ of biotinylated monoclonal antibody $(500 \mathrm{ng} / \mathrm{ml}$; Endogen) in blocking buffer was added and incubated for another 1 hour at room temperature. Plates were washed 4 times and then incubated with PolyStrepHRP (1:5000; Endogen) for 30 minutes at room temperature. After washing, $100 \mu \mathrm{l}$ TMB substrate (BioRad) was added and incubated for 15 minutes. The reaction was stopped with $100 \mu$ l of $0.1 \mathrm{~N}$ sulfuric acid and read at $450 \mathrm{~nm}$ using an ELISA plate reader (Cayman Chemical).

\section{Immunohistochemistry Staining for Ki-67 Nuclear Antigens Associated with Proliferation}

HMC grown on coverslips and fixed as previously detailed were stained using the avidin-biotin technique according to Hsu et al (1981). The monoclonal antibody to Ki-67 (Clone MMI) from Ventana Medical Systems was used prediluted and the staining procedure was performed on the Ventana ES Automated Slide Stainer. HMC were placed on low serum media 48 hours before incubation with PDGF-BB (positive control), or no LC-media alone (negative control) LCDD, AL or T-LC. The overall number of MC per plate was similar as assessed by their confluency and cell counting. The number of $\mathrm{Ki}-67-$ positive nuclei was counted before and 1, 3, 6, and 24 hours after the addition of the LC. At least $150 \mathrm{HMC}$ were counted in each experimental condition. The percentage of positive HMC nuclei was calculated. A group of $\mathrm{HMC}$ also grown on coverslips were pretreated with an antibody to c-fos (sc-52; Santa Cruz; 200-fold dilution, final concentration $1 \mu \mathrm{g} / \mathrm{ml}$ ) for 20 minutes before incubation with LCDD, AL- or T-LC, and without LC (media alone). 


\section{Immunohistochemistry Staining of HMC for PDGF- $\beta$, PDGF- $\beta$ Receptor, and TFG- $\beta$}

HMC grown on coverslips and fixed as previously detailed were stained using the avidin-biotin complex technique according to $\mathrm{Hsu}$ et al (1981). The mouse monoclonal antibodies for PDGF- $\beta$ and PDGF- $\beta$ receptor (Genzyme, Cambridge, Massachusetts) were used at 1:150 dilution. The antibody for TGF- $\beta$ detection was a rabbit polyclonal antibody ( $R$ and $D$ Systems, Minneapolis, Minnesota) used at a dilution of 1:100. Negative controls were generated by replacing the primary antibody with nonspecific rabbit IgG. Avidin-biotin blocking was performed to ensure that all endogenous biotin receptors or avidin sites present in the samples were blocked before the addition of the avidin reagent. The blocking consisted of applying $20 \mathrm{ml}$ of avidin D followed by 20 $\mathrm{ml}$ of biotin before incubation with the primary antibody to PDGF- $\beta$, PDGF- $\beta$ receptor, and TGF- $\beta$. To determine that the staining was specific for the growth factor or receptor tested, antigen excess (four times equimolar amounts) was mixed with the corresponding antibody and then the mixture was applied to the coverslips.

The staining method is outlined below. Briefly, coverslips were rinsed three times in $20 \mathrm{~mm}$ phosphate buffer, $\mathrm{pH} 7.4$, and fixed in $80 \%$ ethanol for 15 minutes. After fixation, the coverslips were rinsed again three times with phosphate buffer, incubated in phosphate buffer containing $1.5 \%$ normal goat serum (Vector Laboratories, Burlingame, California) at $4^{\circ} \mathrm{C}$ for 10 minutes, and incubated with primary antibody at the indicated dilution for 12 hours at $37^{\circ} \mathrm{C}$. Unbound antibody was aspirated and the cells were rinsed three times with phosphate buffer. Coverslips were incubated with biotinylated goat antirabbit or antimouse IgG, depending on the antibody used (Vector Laboratories). After rinsing three times with phosphate buffer, $0.1 \%$ diaminobenzidine tetrahydrochloride in $0.1 \mathrm{M}$ Tris buffer, $\mathrm{pH} 7.2$, with $0.02 \%$ hydrogen peroxide was applied as the substrate of horseradish peroxidase for 5 minutes at $25^{\circ} \mathrm{C}$. Finally, coverslips were washed in tap water for 5 minutes, mounted with Permount (Fisher Scientific) and viewed with a BH-2 Olympus microscope (C. Squared). Immunoreactivity depending on the degree of brown cytoplasmic staining was evaluated in the MC.

Fifty MC from each experimental condition were evaluated. Each MC was graded for the intensity of staining as follows: 0 , no brown cytoplasmic staining; 1 , weak, low-intensity brown cytoplasmic staining less than background nuclear hematoxylin staining; 2, moderate, medium-intensity brown cytoplasmic staining of about the same intensity as the background nuclear hematoxylin staining; and 3 , marked, highintensity brown cytoplasmic staining overshadowing background nuclear hematoxylin staining.

The grade of staining for each one of the 50 cells was totaled for a possible maximum score of 150 per experimental condition. The experiments were repeated in triplicate and the scores were averaged.
The results were tabulated and represented in a graph form.

\section{Statistical Analysis}

ELISA and immunohistochemical data were analyzed for statistical significance by Spearman's rank correlation and analysis of variance. Significance was set at the $5 \%$ level.

\section{References}

Abboud HE (1991). Mesangial cells in glomerular injury. Semin Nephrol 11:299-306.

Abboud HE (1993). Growth factors in glomerulonephritis. Kidney Intl 43:252-367.

Auwardt RB, Mudge SJ, Chen CG, and Power DA (1998). Regulation of nuclear factor $-\kappa \beta$ by corticosteroids in rat mesangial cells. J Am Soc Nephrol 9:1620-1628.

Batuman V and Guan S (1997). Receptor-mediated endocytosis of immunoglobulin light chains by renal proximal tubule cells. Am J Physiol 272:F521-F530.

Batuman V, Verroust PJ, Navar G, Kaysen JH, Goda FO, Campbell WC, Simon E, Pontillon F, Lyles M, Bruno J, and Hammond TG (1998). Myeloma light chains are ligands for cubilin (gp280). Am J Physiol 275:F246-F254.

Border WA, Noble NA, Yamamoto T, Tomooka S, and Kagami S (1992). Antagonists of transforming growth factor- $\beta$ : A novel approach to treatment of glomerulonephritis and prevention of glomerulosclerosis. Kidney Int 41:566570.

Böttinger EP, Letterio JJ, and Roberts AB (1997). Biology of TGF- $\beta$ in knockout and transgenic mouse models. Kidney Int $51: 1355-1360$.

Duque N, Gomez-Guerro C, and Egido J (1997). Interactin of IgA with FC $\alpha$ receptors of human mesangial cells activates transcription factor nuclear factor- $\kappa \beta$ and induces expression and synthesis of monocyte chemoattractant protein-1, IL-8, and IFN-inducible protein 10. J Immunol 159:3474-3482.

Feige JJ and Baird A (1995). Crinopexy: Extracellular regulation of growth factor action. Kidney Int 49(Suppl):S15-S18.

Gallo G, Picken M, Buxbaum J, and Frangione B (1989). The spectrum of monoclonal immunoglobulin deposition disease associated with immunocytic dyscrasias. Semin Hematol 26:234-245.

Harper PA, Robinson JM, Hoover RL, Wright TC, and Karaovsky MJ (1984). Improved methods for cultured rat glomerular cell. Kidney Int 26:875-880.

Herrera GA, Russell WJ, Isaac J, Turbat-Herrera EA, Tagouri YM, Sanders PW, Picken MM, and Dempsey S (1999). Glomerulopathic light chain-mesangial cell interactions modulate in vitro extracellular matrix remodeling and reproduce mesangiopathic findings documented in vivo. Ultrastruct Pathol 23:107-126.

Herrera GA, Shultz J, Soong S, and Sanders PW (1994). Growth factors in monoclonal light chain related renal diseases. Hum Pathol 25:883-892.

Hsu S-M, Raine L, and Fanger H (1981). Use of avidin-biotinperoxidase complex $(\mathrm{ABC})$ in immunoperoxidase techniques: 
A comparison between $\mathrm{ABC}$ and unlabeled antibody (PAP) procedures. J Histochem Cytochem 29:577-580.

Ishikawa Y, Sugiyama H, Stylianou E, and Kitamura M (1999). Bioflavanoid quercetin inhibits interleukin-1-induced transcriptional expression of monocyte chemoattractant protein-1 in glomerular cells via suppression of nuclear factor- $\kappa \beta$. J Am Soc Nephrol 10:2290-2296.

Kon A, Vindevoghel L, Kouba DJ, Fujimura Y, Uitto J, and Mauviel A (1999). Cooperation between SMAD and NF- $\kappa \beta$ in growth factor regulated type VII collagen gene expression. Oncogene 18:1837-1844.

Kopp JB, Factor VM, Mozes M, Nagy P, Sanderson N, Böttinger EP, Klotman PE, and Thorgeirsson SS (1996). Transgenic mice with increased plasma levels of TGF- $\beta 1$ develop progressive renal disease. Lab Invest 74:991-1003.

Lawrence DA (1995). Transforming growth factor- $\beta$ : An overview. Kidney Int 47:S19-23.

Lipkowitz JS, Klotman ME, Bruggeman LA, Nicklin P, Hanss B, Rappaport J, and Klotman PE (1996). Molecular therapy for renal diseases. Am J Kidney Dis 28:475-492.

López-Armada MJ, Gómez-Guerrero C, and Egido J (1996). Receptors for immune complexes activate gene expression and synthesis of matrix proteins in cultured rat and human mesangial cells: Role of TGF- $\beta$. J Immunol 157:2136-2142.

Massy ZA, Guijarro C, O'Donnell MP, Kim Y, Kashtan CE, Egido J, Kasiske BL, and Keane WF (1999). The central role of nuclear factor $-\kappa \beta$ in mesangial cell activation. Kidney Int 71(Suppl):S76-79.

Mellström K, Heldin CH, and Westermark B (1988). Induction of circular membrane ruffling on human fibroblasts by platelet-derived growth factor. Exp Cell Res 177:347-359.

Peters H, Border WA, and Noble NA (1998). Targeting TGF- $\beta$ overexpression in renal disease: Maximizing the antifibrotic action of angiotensin II blockade. Kidney Int 54:1570-1580.

Poncelet AC and Schnaper HW (1998). Regulation of human mesangial cell collagen expression by transforming growth factor- $\beta 1$. Am J Physiol 275:F458-F466.

Richards SA, Fu J, Romanelli A, Shimamura A, and Blenis J (1999). Ribosomal S6 kinase 1 (RSK1) activation requires signal dependent on and independent of the MAP kinase ERK. Current Biol 9:810-820.

Rovin BH, Dickerson JA, Tan LC, and Hebert CA (1995). Activation of nuclear factor $\kappa \beta$ correlates with MCP-1 expression by human mesangial cells. Kidney Int 48:1263-1271.

Rovin BH, Wilmer WA, Danne M, Dickerson JA, Dixon CL, and $L u L$ (1999). The mitogen-activated protein kinase p38 is necessary for interleukin 1beta-induced monocyte chemoattractant protein 1 expression by human mesangial cells. Cytokine 11:118-126.
Ruiz-Ortega M, Bustos C, Hernandez-Presa MA, Lorenzo O, Plaza JJ, and Egido J (1998). Angiotensin II participates in mononuclear cell recruitment in experimental immune complex nephritis through nuclear factor- $\kappa \beta$ activation and monocyte chemoattractant protein-1 synthesis. J Immunol 161:430-439.

Sanders PW and Herrera GA (1993). Monoclonal immunoglobulin light chain-related renal diseases. Semin Nephrol 13:324-341.

Sanders PW, Herrera GA, and Galla JH (1987). Human Bence Jones protein toxicity in rat proximal tubule epithelium in vivo. Kidney Int 32:851-861.

Sanders PW, Herrera GA, Kirk KA, Old CW, and Galla JH (1991). The spectrum of glomerular and tubulointerstitial renal lesions associated with monotypical immunoglobulin light chain deposition. Lab Invest 64:527-537.

Satriano $\mathrm{J}$ and Schlondorff D (1994). Activation and attenuation of transcription factor NF- $\kappa \beta$ in some glomerular mesangial cells in response to tumor necrosis factor- $\alpha$, immunoglobulin G, and adenosine $3^{\prime}-5$ '-cyclic monophosphate. J Clin Invest 94:1629-1636.

Schreiber E, Matthias P, Müller MM, and Schaffner W (1989). Rapid detection of octamer binding proteins with "mini extracts," prepared from a small number of cells. Nucleic Acids Res 17:6419.

Sharma K and Ziyadeh FN (1993). The transforming growth factor- $\beta$ system and the kidney. Semin Nephrol 13:116-128.

Stylianou E, Nie M, Ueda A, and Zhao L (1999). c-Rel and p65 trans-activate the monocyte chemoattractant protein-1 gene in interleukin-1 stimulated mesangial cells. Kidney Int 56: 873-882.

Tagouri YM, Sanders PW, Picken MM, Siegal GP, Kerby JD, and Herrera GA (1996). In vitro AL-amyloid formation by rat and human mesangial cells. Lab Invest 74:290-302.

Valenzuela R and Deodhar SD (1986). Tissue immunofluorescence. In: Rose NR, Friedman H, Fahey JL, editors. Manual of clinical laboratory immunology, 3rd ed. Washington: American Society for Microbiology, 923-925.

Whitman M (1998). Smads and early developmental signaling by the TGF $\beta$ family. Genes Dev 12:2445-2462.

Yan SD, Zhu H, Zhu A, Golabek A, Du H, Roher A, Yu J, Soto C, Schmidt AM, Stern D, and Kindy M (2000). Receptordependent cell stress and amyloid accumulation in systemic amyloidosis. Nat Med 16:643-651.

Zhu L, Herrera GA, Murphy-Ullrich JE, Huang Z-Q, and Sanders PW (1995). Pathogenesis of glomerulosclerosis in light chain deposition disease: Role for transforming growth factor- $\beta$. Am J Pathol 147:375-385. 